Research article

\title{
Purification and kinetic studies of recombinant gibberellin dioxygenases
}

\author{
Diane R Lester ${ }^{* 1}$, Andy Phillips ${ }^{2}$, Peter Hedden ${ }^{2}$ and Inger Andersson ${ }^{3}$
}

\author{
Address: ${ }^{1}$ Institute for Cell and Molecular Biology, Uppsala University, Box 596, 75124 Uppsala, Sweden, ${ }^{2}$ Rothamsted Research, Harpenden, \\ Herts, AL5 2JQ UK and '3epartment of Molecular Biology, Swedish University of Agricultural Sciences, Box 590, 75124 Uppsala, Sweden \\ Email: Diane R Lester* - diane@xray.bmc.uu.se; Andy Phillips - andy.phillips@bbsrc.ac.uk; Peter Hedden - peter.hedden@bbsrc.ac.uk; \\ Inger Andersson - inger@xray.bmc.uu.se \\ * Corresponding author
}

Published: 25 September 2005

BMC Plant Biology 2005, 5:19 doi:10.1 186/1471-2229-5-19
Received: 27 May 2005

Accepted: 25 September 2005

This article is available from: http://www.biomedcentral.com/I47/-2229/5//9

(C) 2005 Lester et al; licensee BioMed Central Ltd.

This is an Open Access article distributed under the terms of the Creative Commons Attribution License (http://creativecommons.org/licenses/by/2.0), which permits unrestricted use, distribution, and reproduction in any medium, provided the original work is properly cited.

\begin{abstract}
Background: The 2-oxoglutarate-dependent dioxygenases (2ODDs) of gibberellin (GA) biosynthesis have a key role in the metabolism of a major plant hormone. The activity of recombinant GA 2ODDs from many species has been characterised in detail, however little information relates to enzyme purification. Native GA 2ODDs displayed lability during purification.

Results: Two GA 2ODDs were expressed in Escherichia coli and purified to homogeneity. The GA 2-oxidase from Pisum sativum L., PsGA2OXI, was expressed as a glutathione s-transferase (GST) fusion. It was purified in the three steps of affinity chromatography, GST removal and gel filtration. Highly pure PsGA2OXI was obtained at a yield of $0.3 \mathrm{mg} / \mathrm{g}$ of cells. It displayed a $K_{\mathrm{m}}$ of $0.024 \mu \mathrm{M}$ and a $V_{\max }$ of $4.4 \mathrm{pkat} / \mathrm{mg}$ toward [ $\left[\beta, 2 \beta, 3 \beta-{ }^{3} \mathrm{H}_{3}\right] \mathrm{GA}_{20}$. The GA 3-oxidase from Arabidopsis thaliana, AtGA3OX4, was expressed as a poly(His)-tagged thioredoxin fusion. It was purified by Immobilised Metal Affinity Chromatography followed by gel filtration. Cleavage of the fusion took place between the two purification steps. Highly pure AtGA3OX4 was obtained at a yield of $0.01 \mathrm{mg} / \mathrm{g}$ of cells. It displayed a $K_{m}$ of $0.82 \mu \mathrm{M}$ and $V_{\text {max }}$ of 52,500 pkat $/ \mathrm{mg}$ toward $\left[1 \beta, 2 \beta, 3 \beta-{ }^{3} \mathrm{H}_{3}\right] \mathrm{GA}_{20}$.

Conclusion: Fusion tags were required to stabilise and solubilise PsGA2OXI and AtGA3OX4 during $E$. coli expression. The successful purification of milligram quantities of PsGA2OXI enables mechanistic and structural studies not previously possible on GA 2ODDs. A moderate yield of pure AtGA3OX4 requires the further optimisation of the latter stages of the enzyme purification schedule. PsGA2OXI's action in planta as deduced from the effect of the null mutation sin on GA levels in seeds is in agreement with the kinetic parameters of the recombinant enzyme.
\end{abstract}

\section{Background}

The 2-oxoglutarate-dependent dioxygenases (2ODDs) of gibberellin (GA) biosynthesis have a key role in plant hormone metabolism. Three principal classes of 2ODDs control the later stages of the pathway where bioactive GA is produced and inactivated (Figure 1). Activation and deac- tivation of the GA molecule are performed by GA 3-oxidase and GA 2-oxidase enzymes, respectively.

The genes encoding GA 2ODDs have been described from many species. They belong to multigene families which show spatial and temporal patterns of expression [1]. Factors including hormone levels and light have been shown 


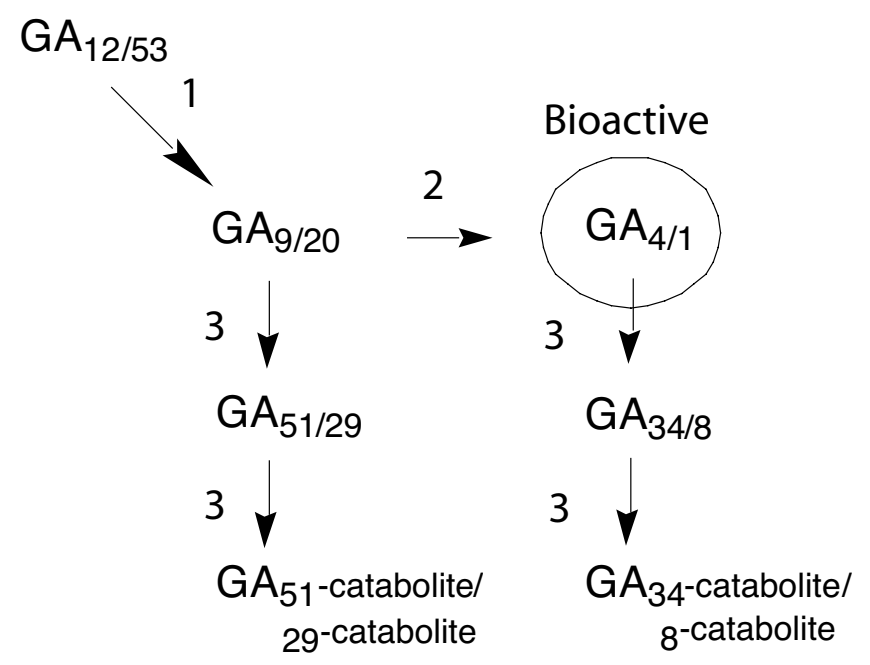

\section{Figure I}

The latter steps of biosynthesis of non- I 3-hydroxylated/I3hydroxylated GAs. The steps surrounding production of bioactive GAs in higher plants are catalysed by the 2-oxoglutarate-dependent dioxygenases (2ODDs); I GA 20-oxidase, 2 GA 3-oxidase and 3 GA 2-oxidase. In pea the I3-hydroxylated pathway predominates; in Arabidopsis the non-13hydroxylated pathway generally predominates, however developing seeds contain comparable levels of non-13hydroxylated and I3-hydroxylated GAs [18]. The s/n phenotype of pea arises from a null mutation affecting the predominant GA 2-oxidase (PsGA2OXI) of maturing seeds (steps $3)$. In this study the activities of a pea GA 2-oxidase (PsGA2OXI) and arabidopsis GA 3-oxidase (AtGA3OX4) are both assayed using the substrate $\left[\mathrm{I} \beta, 2 \beta, 3 \beta-{ }^{3} \mathrm{H}_{3}\right] \mathrm{GA}_{20}$. It should be noted that in addition both enzymes are likely to use $\mathrm{GA}_{9}$ as a natural substrate.

to influence GA 2ODD gene expression [2], suggesting that the enzymes are important in regulating the overall GA pathway. The genetic manipulation of GA levels for agricultural purposes has often involved 2ODD-catalysed steps.

The GA 2ODDs are well suited to in vitro studies because they retain good activity when expressed in Escherichia coli and their natural substrates are mostly known and available in synthetic form. Thus, a reasonable amount of data relates to the activity of recombinant GA 2ODDs, e.g. [37]. Their catalysis generally appears to reflect that of the native enzymes.

Unfortunately, the excellent literature on the activity of recombinant GA 2ODDs is accompanied by a lack of progress on their purification and structural characterisation. In native form the enzymes displayed a lability that hindered their complete purification [8-11]. The prob- lems associated with this lability have ostensibly not been overcome through using recombinant expression methods. The sole report on a pure GA 2ODD relates to a native GA 20-oxidase from pumpkin endosperm [12].

Herein, we report the successful purification of a recombinant GA 2-oxidase from Pisum sativum L. (pea) and a GA 3-oxidase from Arabidopsis thaliana (Arabidopsis), findings that represent a significant step for an important group of enzymes.

\section{Results \\ Expression and purification of the GA 2-oxidase, PsGA2OXI}

The pea GA 2-oxidase, PsGA2OX1, accumulated intact and in soluble form in E. coli when expressed as a GST fusion in pGEX. The expression conditions employed were determined to be optimal with respect to incubation temperature and induction conditions. Trials with a GST fusion expression system driven by the stronger T7 promoter did not improve expression levels (results not shown).

Affinity chromatography of GST-PsGA2OX1 from the soluble cell fraction gave a high degree of purification (Figure 2A). Subsequent removal of the GST tag yielded PsGA2OX1 with only two major contaminants (Figure 2A). Gel filtration removed these contaminants without significant loss of PsGA2OX1 and increased its purity to > $95 \%$ as estimated from SDS-PAGE analysis (Figure 2B). Pure PsGA2OX1 was obtained in milligram quantities and was concentrated to $10 \mathrm{mg} / \mathrm{mL}$ (Figure $2 \mathrm{~B}$, Table 1).

PsGA2OX1 was active at all stages of purification (Table 1). EDTA had an inhibitory effect on activity that was removed most effectively by dialysis rather than dilution. However, when crude samples were dialysed, activity diminished, presumably because of enzyme inactivation or degradation. In addition, endogenous components of E. coli lysates are suspected to inhibit GA 2ODDs [7]. Therefore, the activity measurements after the first two stages of purification (Table 1) gave apparent values.

Concentrated highly pure PsGA2OX1 retained activity after storage at $-70^{\circ} \mathrm{C}$.

\section{Kinetic analysis of PsGA2OXI}

The activity of this pure PSGA2OX1 displayed a saturation curve of the Michaelis Menten type in response to increasing concentration of substrate $\left[{ }^{3} \mathrm{H}_{3}\right] \mathrm{GA}_{20}$ (Figure 3 ). The $K_{M}$ was calculated to be $0.024 \mu \mathrm{M}$ and the $V_{\max } 4.4$ pkat/ $\mathrm{mg}$. 
Table I: Purification of PsGA2OXI from E. coli cells (approx. $6 \mathrm{~g}$ )

\begin{tabular}{|c|c|c|c|c|c|}
\hline Purification step & Protein $(\mathrm{mg})$ & Specific activity* (pkat/mg) & Total activity (pkat)* & $\begin{array}{l}\text { Apparent purification } \\
\text { factor* }\end{array}$ & Yield* \\
\hline Soluble cell fraction & 670 & 0.013 & 8.71 & - & - \\
\hline $\begin{array}{l}\text { Affinity chromatography (after GST } \\
\text { removal) }\end{array}$ & 3.8 & 0.320 & 1.2 & $24 X$ & $14 \%$ \\
\hline Superdex 75 & 1.8 & 0.89 & 1.6 & $2.8 \mathrm{X}$ & $18 \%$ \\
\hline
\end{tabular}

*Figures influenced by EDTA of buffers in the first two steps

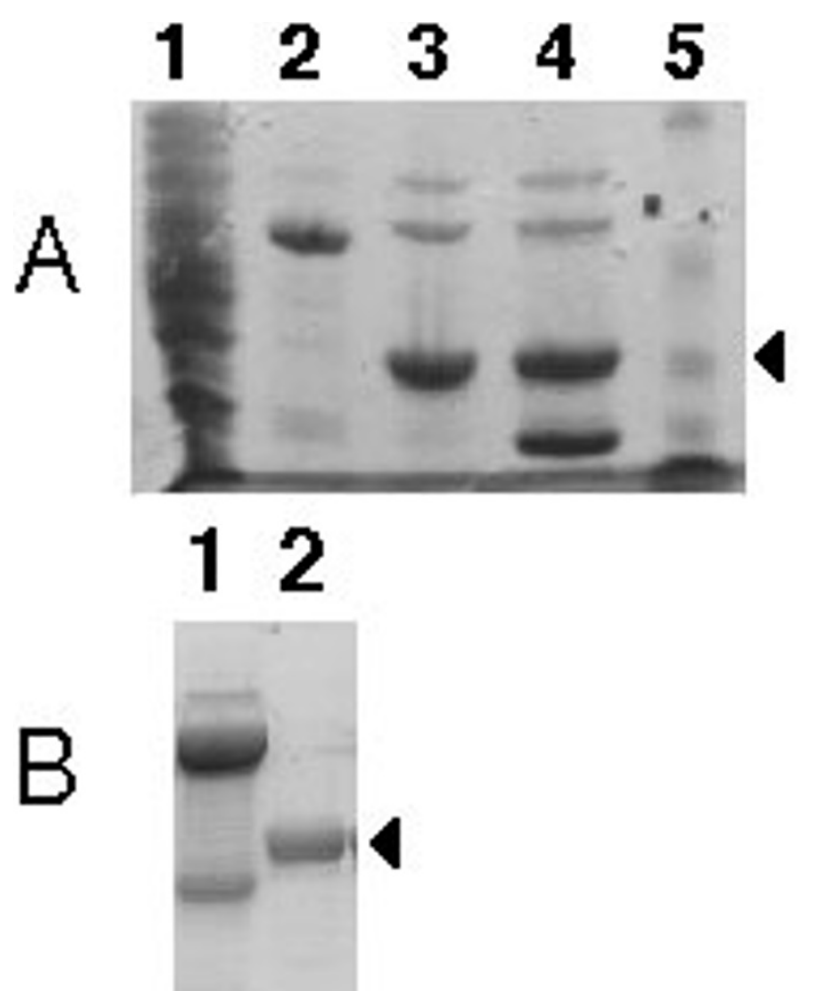

Figure 2

Purification of recombinant PsGA2OXI shown by SDSPAGE on a $12 \%$ gel with Coomassie Blue staining. (A) Lanes: I, soluble cell fraction; 2, GST-PsGA2OXI after affinity chromatography; 3, PSGA2OXI after thrombin digest and GST removal; 4, thrombin digest of GST-PsGA2OXI with GST present; 5, Bio Rad molecular weight standards, (from top) 93, 49.8, 35.8, 29.2 and $21.3 \mathrm{kDa}$. (B) Lanes: I, concentrated GST-PsGA2OXI (uncleaved, $10 \mathrm{mg} / \mathrm{mL}$ ); 2, concentrated PsGA2OXI (10 mg/mL) after gel filtration on Superdex 75 . The molecular weights expected for GST-PsGA2OXI, PsGA2OXI and GST are 62.8, 36.8 and $26 \mathrm{kDa}$, respectively. The arrows indicate the position of PsGA2OXI.

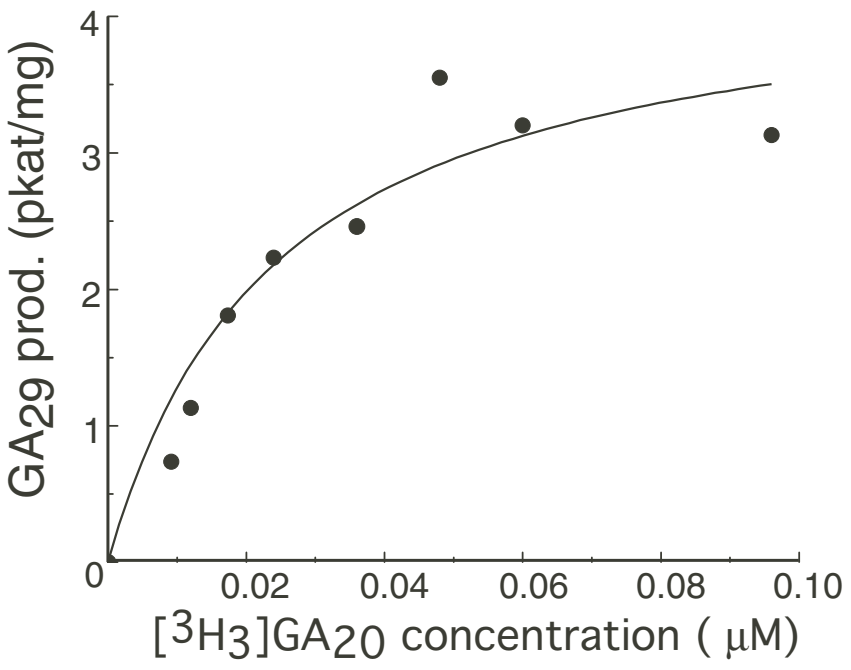

Figure 3

Michaelis-Menten plot for highly pure PsGA2OXI with the substrate $\left[{ }^{3} \mathrm{H}_{3}\right] \mathrm{GA}_{20}$. Origin (Microcal) was used to draw the plot and calculate the kinetic parameters. The $K_{M}$ was calculated as $0.024 \mu \mathrm{M}$ and the $V_{\max }$ as $4.4 \mathrm{pkat} / \mathrm{mg}$.

\section{Expression and purification of the GA 3-oxidase, AtGA3OX4}

The Arabidopsis GA 3-oxidase, AtGA3OX4, accumulated intact and in soluble form when expressed as a poly(His)tagged TRX fusion in pET32 to a level that was discernible by SDS-PAGE analysis of the soluble cell fraction (Figure 4A).

During purification AtGA3OX4 tended to precipitate, although precipitation could be minimised during the first step by dilution of the soluble cell lysate and the use of a buffer of $\mathrm{pH} 6.3$ with $10 \mathrm{mM} \beta$-ME.

TRX-AtGA3OX4 was purified to a high degree by Immobilised Metal Affinity Chromatography (Figure 4A, Table 2). Cleavage of the TRX tag from AtGA3OX4 was enabled by a thrombin site engineered into the expression construct - the Factor Xa site encoded by pET32 failed to cleave. 

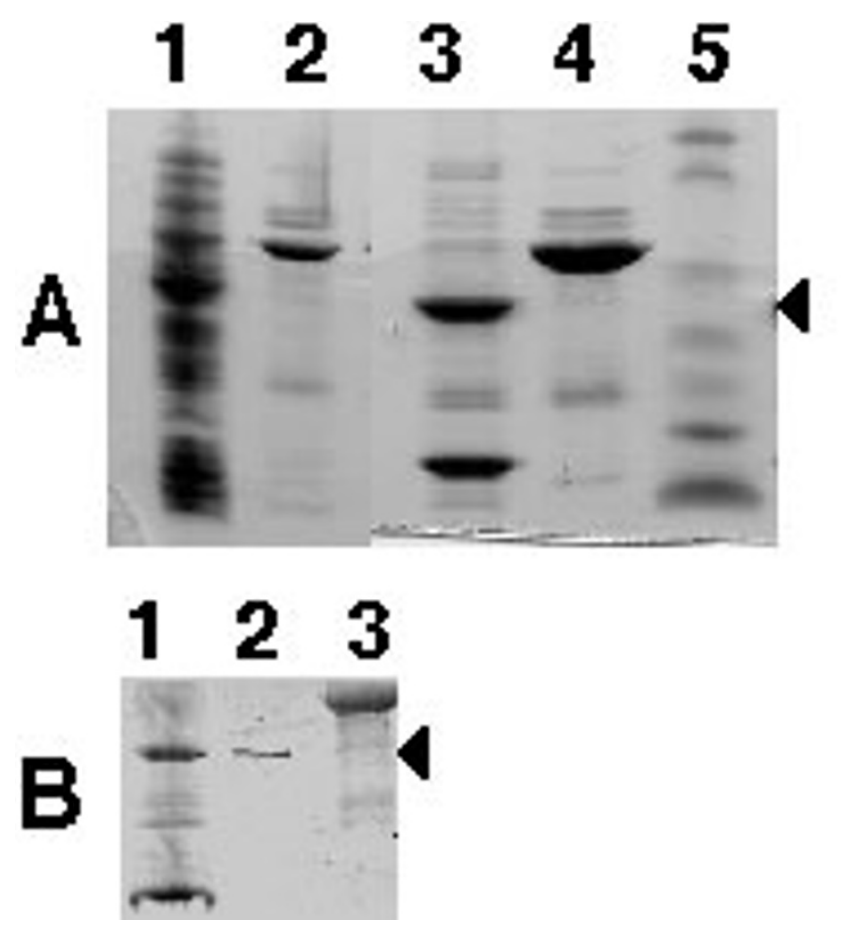

Figure 4

Purification of recombinant AtGA3OX4 shown by SDSPAGE on a 8-15\% gradient gel with Coomassie Blue staining.(A) Lanes: I, soluble cell fraction; 2, TRX-AtGA3OX4 after IMAC chromatography; 3, TRX-AtGA3OX4 after thrombin digest; 4, concentrated TRX-AtGA3OX4 (10 mg/ $\mathrm{mL}$ ); 5, Bio Rad molecular weight standards, (from top) II 5 , 93, 49.8, 35.8, 29.2, 21.3 and 6.4 kDa.(B) Lanes: I, TRXAtGA3OX4 after thrombin digest; 2, AtGA3OX4 (I.5 mg/ $\mathrm{mL}$, maximal concentration achieved) after gel filtration on Superdex 75; 3, TRX-AtGA3OX4 (10 mg/mL) after gel filtration on Superdex 200. The molecular weights expected for TRX-AtGA3OX4, AtGA3OX4 and TRX are 54.I, 39.I and I $5 \mathrm{kDa}$, respectively. The arrows indicate the position of AtGA3OX4.

AtGA3OX4 was difficult to separate from TRX, remaining strongly associated with it subsequent to thrombin cleavage. The single factor identified that most obviously mitigated this association was $\beta$-ME, with low $\mathrm{pH}$ further aiding separation. Resolution of the two proteins was achieved by gel filtration in a buffer of $\mathrm{pH}$ of 5.8 with 10 mM $\beta$-ME. Highly pure AtGA3OX4 was thus obtained in microgram quantities (Figure $4 \mathrm{~B}$, Table 2 ).

Once pure, AtGA3OX4 resisted concentration. The problem was partially overcome by the addition of Triton X100. However, the maximum concentration of AtGA3OX4 achieved was $1.5 \mathrm{mg} / \mathrm{mL}$ and its activity did not tolerate freezing.

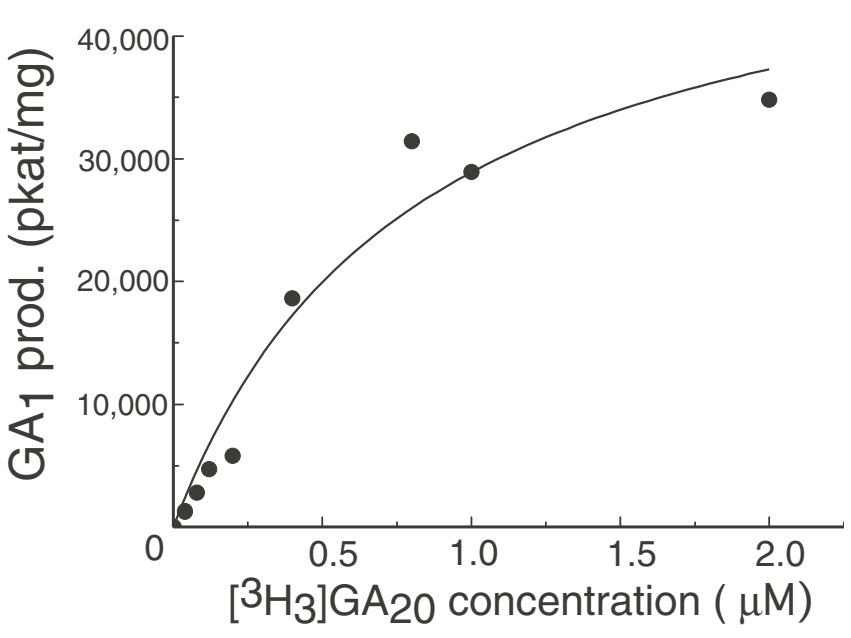

Figure 5

Michaelis-Menten plot for highly pure AtGA3OX4 with the substrate $\left[{ }^{3} \mathrm{H}_{3}\right] \mathrm{GA}_{20}$. Origin (Microcal) was used to draw the plot and calculate the kinetic parameters. The $K_{M}$ was calculated as $0.85 \mu \mathrm{M}$ and the $V_{\max }$ as 52,500 pkat $/ \mathrm{mg}$.

Otherwise, AtGA3OX4 was active at all stages of purification, permitting a kinetic study on highly pure AtGA3OX4.

Removal of the TRX tag had no obvious affect on AtGA3OX4 activity levels. Triton X-100 had an inhibitory effect but this seemed to disappear with dilution. The use of low pH buffers during purification did not obviously dampen AtGA3OX4's activity. Indeed, we found AtGA3OX4 displayed $80 \%$ activity when assayed in the phosphate buffer of $\mathrm{pH} 6.3$ used for the first purification step, providing the reducing agent DTT was present (results not shown). However, the buffer of pH 5.8 in the second step was not compatible with activity assays.

In light of the difficulties associated with obtaining AtGA3OX4 in high yield, further purification of the fusion, TRX-AtGA3OX4, was conducted. Milligrams of highly pure TRX-AtGA3OX4 were obtained. The protein was amenable to concentration (Figure 4B) and could be frozen at $-70^{\circ} \mathrm{C}$ without activity loss.

\section{Kinetic analysis of AtGA3OX4}

The activity of highly pure AtGA3OX4 displayed a saturation curve of the Michaelis Menten type in response to increasing concentration of $\left[{ }^{3} \mathrm{H}_{3}\right] \mathrm{GA}_{20}$ (Figure 5). The $K_{M}$ was calculated to be $0.82 \mu \mathrm{M}$ and the $V_{\max } 52,500$ pkat/ mg. 
Table 2: Purification of AtGA3OX4 from E. coli cells (approx. $7 \mathrm{~g}$ )

\begin{tabular}{llllll}
\hline Purification step & Protein $(\mathrm{mg})$ & $\begin{array}{l}\text { Specific activity (pkat/ } \\
\mathrm{mg})\end{array}$ & Total activity (pkat) & $\begin{array}{l}\text { Apparent purification } \\
\text { Factor }\end{array}$ & Yield (\%) \\
\hline $\begin{array}{l}\text { Soluble cell fraction } \\
\text { IMAC }\end{array}$ & 790 & 360 & 284,400 & - & - \\
$\begin{array}{l}\text { chromatography } \\
\text { Superdex 75 }\end{array}$ & 4.0 & 4,325 & 17,300 & $12 \times$ & $6 \%$ \\
\hline
\end{tabular}

\section{Discussion}

High levels of activity are frequently obtained for GA 2ODDs in E. coli expression systems in the absence of accumulated soluble enzyme [13]. The instability generally reported in native 2ODDs appears to be a feature of the recombinant enzymes. In early trials of GA 2ODDs, the pea GA 2-oxidase, PsGA2OX1, and the Arabidopsis GA 3-oxidase, AtGA3OX4, showed promise as candidates for purification (D.R. Lester, unpublished). In both cases, a N-terminal fusion tag was needed to obtain soluble intact protein.

The purification of the pea GA 2-oxidase, PsGA2OX1, was straightforward. No problems were encountered during chromatography, tag removal or enzyme concentration. All steps of purification were performed in a buffer that preserved enzyme activity. The $\mathrm{pH}$ was within physiological range when the chelator EDTA and the reducing agent DTT were present. (The latter were considered desirable because PsGA2OX1 is $\mathrm{Fe}^{++}$-dependent and its active site is likely to be susceptible to metal-catalysed oxidation). The milligram amounts of PsGA2OX1 that we obtained are unprecedented for a highly pure GA 2ODD.

The gene encoding PsGA2OX1 is affected by the null mutation, $\sin$, which causes the accumulation of $\mathrm{GA}_{20}$ within maturing pea seed $[14,15]$. The mutation has a lesser effect on $\mathrm{GA}_{20}$ levels in the stem, presumably because other GA 2-oxidases compensate for its loss in this tissue. Mature seeds contain at least two GA 2-oxidases $[11,14]$. The $\sin$ phenotype indicates that PsGA2OX1 is the main catalyst for the conversion $\mathrm{GA}_{20}$ to $\mathrm{GA}_{29}$ at latter stages of seed maturation, when 2-oxidation of $\mathrm{GA}_{20}$ takes place at high levels. Although the $\sin$ mutation is not deleterious to developing seeds, the mature seeds contain abnormally high amounts of $\mathrm{GA}_{20}$, which, after germination, is converted to the bioactive $\mathrm{GA}_{1}$ resulting in the slender (overgrowth) phenotype of the seedling [16]. The levels of $\mathrm{GA}_{20}$ present in mature $S L N$ and $\sin$ seeds are $11 \mathrm{ng} / \mathrm{g}$ and 4,118 ng/g, respectively [16]. The difference can be solely attributed to the action of PsGA2OX1 in planta.
Multiple GA 2-oxidases have been previously partially purified in low yield from pea seeds of unspecified maturity [11]. The incomplete purification was attributed to a low abundance of the enzymes in the tissue, and instability during purification. It can be assumed that native PsGA2OX1 was among these GA 2-oxidases because its gene is expressed throughout seed maturation [15]. Recombinant expression methods have now enabled us to complete the successful purification of PsGA2OX1.

At $0.024 \mu \mathrm{M}$, the $K_{M}$ of recombinant PsGA2OX1 toward $\mathrm{GA}_{20}$ was much lower than that obtained for the native pea seed GA 2-oxidases $(1.55 \mu \mathrm{M})$ [11]. The comparison of $K_{M}$ results is complicated, however, because the native preparation contained multiple activities. Certainly, a high substrate affinity of PsGA2OX1 is consistent with its ability to clear the maturing seed of $\mathrm{GA}_{20}$.

The gene encoding PsGA2OX1 is expressed relatively strongly throughout the latter weeks of pea seed maturation [15]. That the enzyme is abundant in mature seeds was supported by a study of GA 2-oxidases from this tissue in the related species Phaseolus vulgaris [8]. If present in abundance, it is plausible that PsGA2OX1 ( $V_{\max }$ of 4.4 pkat/mg) could account for the difference in $\mathrm{GA}_{20}$ levels between $S L N$ and $\sin$ seeds.

The $V_{\max }$ of the partially pure native GA 2-oxidases toward $\mathrm{GA}_{20}$ was $24.8 \mathrm{pmol} / \mathrm{h} \mathrm{mg} \mathrm{(0.0068} \mathrm{pkat/mg)} \mathrm{[11].} \mathrm{The}$ higher figure of the recombinant enzyme suggests that its purity and/or retention of activity was enhanced compared with the native preparation. Interestingly, the $V_{\max }$ of PsGA2OX1 was several orders of magnitude lower than the $V_{\max }$ of AtGA3OX4 toward $\mathrm{GA}_{20}$ (Figure 5). However, this difference is difficult to interpret considering the two enzymes are from different species and are likely to be expressed differentially within the plant alongside isoenzymes.

With their role in GA activation, the GA 3-oxidases are particularly interesting to study, but in native form the enzymes are difficult to purify. It required 6,661 immature seeds for Kwak et al. [9] to obtain $0.086 \mathrm{mg}$ of 
enzyme described as partially pure. Recombinant methods enabled us to partially overcome the problems associated with purification of a recombinant GA 3-oxidase. Our experience provides valuable insight for future work.

The first step we used in the purification of the Arabidopsis GA 3-oxidase, AtGA3OX4, was IMAC chromatography. This method does not permit the inclusion of DDT or EDTA in buffers and therefore has been considered unsuitable for purifying 2ODDs [17]. Nonetheless, AtGA3OX4 with high specific activity was obtained using this method. Evidently, $10 \mathrm{mM} \beta$-ME was able to protect the enzyme active site from metal-catalysed oxidation during chromatography. The result suggests that this widely used and highly efficient purification strategy does not necessarily compromise the activity of a 2ODD.

AtGA3OX4 showed a tendency to precipitate, one that became more pronounced when it was cleaved, but not physically separated, from TRX. This diminished the yield of the protein, particularly in the final step. A beneficial effect from low $\mathrm{pH}$ and $\beta$-ME implied that an exposed cysteine was causing the precipitation. However, a combination of factors were probably to blame because the aforementioned conditions did not fully overcome the problem. Furthermore, replacement by site-directed mutagenesis of the cysteine predicted as most likely to be exposed (residue 9) brought no improvement. Certainly, AtGA3OX4 displayed hydrophobic behaviour when pure, sticking to tubes unless Triton X-100 was present. Hydrophobicity was also a feature of the GA 3-oxidase of bean [9].

Good scope exists for further optimisation of the AtGA3OX4 purification method. Efficient separation of AtGA3OX4 and TRX will lead to a greatly increased yield. Hydrophobic interaction chromatography is a possible alternative to gel filtration in separating the two proteins.

AtGA3OX4 was amenable to concentration and freezing in the presence of TRX, whether or not it was chemically attached to it. The identification of buffer ingredients that replace TRX's stabilising role, such as alternative detergents, salts or organic solvents may improve the behaviour of purified AtGA3OX4.

AtGA3OX4 is encoded by a member of a family of four GA 3-oxidase genes in Arabidopsis. Generally the non-13hydroxylated GA pathway predominates in Arabidopsis, however recent studies found comparable levels of non13-hydroxylated and 13-hydroxylated GAs in developing seeds [18]. This tissue is the main site of expression of the gene encoding AtGA3OX4 (AtGenExpress microarray data), therefore $\mathrm{GA}_{20}$ is likely to be a natural substrate of AtGA3OX4. The high $V_{\max }$ gained here shows that
AtGA3OX4 can efficiently metabolise $\mathrm{GA}_{20}$. The value of $52,500 \mathrm{pkat} / \mathrm{mg}$ is higher than the $V_{\max }$ of $62 \mathrm{nmol} / \mathrm{min}$ $\mathrm{mg}(1,033 \mathrm{pkat} / \mathrm{mg})$ reported for a purified GST fusion of another Arabidopsis GA 3-oxidase, AtGA3OX1 [7]. AtGA3OX4's $K_{M}$ of $0.82 \mu \mathrm{M}$ toward $\mathrm{GA}_{20}$ was lower than that of AtGA3OX1 $(10 \mu \mathrm{M})[6,7]$, yet higher than the value for the bean seed GA 3-oxidase $(0.29 \mu \mathrm{M})$ [9]. Accumulated kinetic information with respect to both 13hydroxylated and non-13-hydroxylated GAs on each of the GA 3-oxidases of Arabidopsis will give valuable insight into the control of active hormone levels in this model species.

\section{Conclusion}

The previous lack of reports on the complete purification of GA 2-oxidases and GA 3-oxidases is probably due to a combination of their lability and their low abundance in most plant tissues. One might speculate that a crucial role in the control of active hormone levels requires a short enzyme half-life. This study on PsGA2OX1 and AtGA3OX4 shows that GA 2-oxidases and GA 3-oxidases are not necessarily inherently unstable and can be purified active from $E$. coli expression systems under standard conditions. Indeed, the GA 2-oxidase, PsGA2OX1, was exceptionally stable throughout purification. Problems were encountered with the Arabidopsis GA 3-oxidase, AtGA3OX4, due to its hydrophobicity and the presence of hydrostatic charges, rather than metal-catalysed autocleavage or proteolytic breakdown.

Indeed, plant 2ODDs from secondary metabolic pathways are also problematic during purification $[17,19]$. Yet in some cases, they have been purified in high yield permitting detailed structural and mechanistic studies $[20,21]$. We note the recent elucidation of the structure of the labile 2ODD-related enzyme, ACC-oxidase, of ethylene biosynthesis [22]. Our work opens the door to similar studies on the GA 2ODDs.

\section{Methods}

\section{Expression of PsGA2OXI}

The cDNA PsGA2ox1 (GenBank AF100954) was ligated into the EcoRI site of the tac promoter-based E. coli expression vector pGEX4T2 (Amersham Biosciences).

A culture of $100 \mathrm{~mL}$ LB broth with $100 \mu \mathrm{g} / \mathrm{mL}$ ampicillin was inoculated with E. coli BL21 (DE3) pGEX4/PsGA2ox1 and grown overnight at $37^{\circ} \mathrm{C}$ with shaking. Thirty $\mathrm{mL}$ of starter culture was used to inoculate each of 3 flasks containing $1 \mathrm{~L}$ of LB broth with $100 \mu \mathrm{g} / \mathrm{mL}$ ampicillin. Flasks were shaken at $220 \mathrm{rev} / \mathrm{min}$ on a circular orbit of $2.54 \mathrm{~cm}$ at $37^{\circ} \mathrm{C}$. Protein expression was induced when cells reached the $\mathrm{OD}_{600}$ of 1.0. After $2 \mathrm{~h}$ cells were harvested, washed with $1 \mathrm{X}$ PBS and frozen at $-70^{\circ} \mathrm{C}$. 


\section{Purification of PsGA2OXI}

The GST-PsGA2OX1 purification was performed with glutathione agarose beads (Amersham Biosciences) at $4{ }^{\circ} \mathrm{C}$ according to the manufacturer's instructions with the following additional details. The buffer used for the lysis of cells and washing of beads was $50 \mathrm{mM}$ Tris- $\mathrm{HCl} \mathrm{pH} \mathrm{8,300}$ $\mathrm{mM} \mathrm{NaCl}, 5 \mathrm{mM}$ EDTA, $5 \mathrm{mM}$ DTT and $0.4 \mathrm{mM}$ PMSF. Cells (approximately $6 \mathrm{~g}$ ) were resuspended in $120 \mathrm{~mL}$ of buffer and lysozyme was added to $0.1 \mu \mathrm{g} / \mathrm{mL}$. After incubation at room temperature for $15 \mathrm{~min}$, cells were lysed with a Vibra Cell sonicator at $65 \%$ amplitude for a total of $60 \mathrm{sec}$. The cell lysate was spun at 20,000 $\mathrm{g}$ and then GSTPsGA2OX1 was extracted from the supernatant using a bed volume of $2 \mathrm{~mL}$ of beads in batch mode. After a final wash, the beads were resuspended in $2 \mathrm{~mL}$ of buffer containing $10 \mathrm{U}$ of bovine thrombin (Sigma) and incubated at $4^{\circ} \mathrm{C}$ overnight. Thrombin was extracted from the supernatant containing cleaved PsGA2OX1 using benzamidine agarose beads (Amersham Biosciences).

The protein solution was concentrated to a volume of 300 $\mu \mathrm{L}$ using a Vivascience spin concentrator and applied to a Superdex 75 column (Amersham Biosciences). Gel filtration was performed at $6^{\circ} \mathrm{C}$ in the same buffer as was used for affinity chromatography. After separation, fractions containing PsGA2OX1 were pooled and dialysed versus 10 mM Tris-HCl pH 8.0, 1 mM DTT.

Pure PsGA2OX1 protein was concentrated to $10 \mathrm{mg} / \mathrm{mL}$ using a Vivascience spin concentrator and frozen.

\section{Expression of AtGA3OX4}

The cDNA AtGA3ox4 (GenBank AAG52440) from Arabidopsis thaliana was amplified by PCR using Advantage cDNA polymerase mix (Clontech) with the forward primer 5'- GGTATTGAGGGTCGCCTGGTGCCACGCGGTTCTATGCCTTCACTAGCAGAAGAG-3' and reverse primer 5'-AGAGGAGAGTTAGAGCCTTAATTGGTGGGATTAACGAC-3'.

The cDNA was inserted into the T7 promoter-based expression plasmid pET32 Xa/LIC (Novagen) using ligation independent cloning according to the manufacturer's instructions. The resulting construct expressed AtGA3OX4 with an N-terminal tag of both poly(His) and thioredoxin (TRX). A thrombin site was adjacent to the $\mathrm{N}$-terminal of AtGA3OX4, encoded by the forward PCR primer.

A culture of $100 \mathrm{~mL}$ LB broth with $100 \mu \mathrm{g} / \mathrm{mL}$ ampicillin was inoculated with E. coli BL21 (DE3) pET32/AtGA3ox4 and grown overnight at $37^{\circ} \mathrm{C}$ with shaking. Thirty $\mathrm{mL}$ of starter culture was used to inoculate each of 3 flasks containing $1 \mathrm{~L}$ of LB broth with $100 \mu \mathrm{g} / \mathrm{mL}$ ampicillin. The flasks were incubated at $37^{\circ} \mathrm{C}$ with shaking at $220 \mathrm{rev} /$ min on a circular orbit of $2.54 \mathrm{~cm}$ until the $\mathrm{OD}_{600}$ reached
1.0. IPTG was added to $1 \mathrm{mM}$ and the cultures were grown for a further $3 \mathrm{~h}$. Cells were harvested by centrifugation, washed with $1 \mathrm{X}$ PBS and frozen at $-20^{\circ} \mathrm{C}$.

\section{Purification of AtGA3OX4}

Cells (approximately $7 \mathrm{~g}$ ) were thawed and resuspended at room temperature in $120 \mathrm{~mL}$ of $5 \mathrm{mM}$ imidazole, 10 $\mathrm{mM} \beta$-ME, 1X PBS pH 6.3 with $100 \mu \mathrm{g} / \mathrm{mL}$ lysozyme. Cell lysis was performed in a tube on ice using a Vibra Cell sonicator at $65 \%$ amplitude for 6 bursts of $10 \mathrm{~s}$. The lysate was centrifuged at $20,000 \mathrm{~g}$ at $4{ }^{\circ} \mathrm{C}$ and the soluble fraction was retained and kept on ice. Two more $10 \mathrm{~s}$ bursts of sonication were performed to remove high molecular weight DNA. The soluble fraction was diluted to a total volume of $300 \mathrm{~mL}$ with $1 \mathrm{X}$ PBS $\mathrm{pH}$ 6.3, $5 \mathrm{mM}$ imidazole, $10 \mathrm{mM} \beta$-ME.

All column chromatography steps in the purification of AtGA3OX4 were performed at $6^{\circ} \mathrm{C}$.

The crude protein solution was passed over a $5 \mathrm{~mL}$ HiTrap Chelating column (Amersham Biosciences) loaded with $\mathrm{Ni}^{++}$using an Äkta Purifier chromatography system. The column was washed with $50 \mathrm{~mL}$ of $5 \mathrm{mM}$ imidazole, 10 $\mathrm{mM} \beta$-ME, 1X PBS pH 6.3 and the poly(His) TRXAtGA3OX4 was eluted with a linear gradient of $0-200$ $\mathrm{mM}$ imidazole, $10 \mathrm{mM} \beta-\mathrm{ME}$, $1 \mathrm{X}$ PBS $\mathrm{pH}$ 6.3. Fractions containing TRX-AtGA3OX4 were pooled and bovine thrombin (Sigma, $20 \mathrm{U}$ ) was added.

After incubation at $6^{\circ} \mathrm{C}$ overnight, cleaved protein was concentrated and loaded onto a Superdex 75 column equilibrated with $1 \mathrm{X}$ PBS pH 5.8, $10 \mathrm{mM} \beta$-ME. Fractions containing AtGA3OX4 were pooled and concentrated to $1.5 \mathrm{mg} / \mathrm{mL}$ with $1 \%$ Triton X-100.

In parallel experiments, the intact fusion TRX-AtGA3OX4 was further purified by gel filtration on Superdex 200 with $1 \mathrm{X}$ PBS $\mathrm{pH} 5.8,10 \mathrm{mM} \beta$-ME. The purest fractions were pooled, protein was concentrated to $10 \mathrm{mg} / \mathrm{mL}$ and dialysed against $10 \mathrm{mM}$ Tris- $\mathrm{HCl} \mathrm{pH}$ 8.0, $2 \mathrm{mM} \beta$-ME.

Protein concentrations were measured with the Bradford method.

\section{Activity assays on the substrate GA20}

The substrate $\left[1 \beta, 2 \beta, 3 \beta^{-3} \mathrm{H}_{3}\right] \mathrm{GA}_{20}$ (approx. $0.4 \mathrm{TBq} /$ mmole [23]), enabled the measurement of activity from both PsGA2OX1 and AtGA3OX4 via the formation of tritiated water. Quantitative estimates of product formation were possible because the ${ }^{3} \mathrm{H}$ was incorporated at a ratio of $1: 4: 4$ at the $1 \beta, 2 \beta$ and $3 \beta$ positions [23]. The conversion $\mathrm{GA}_{29}$ to $\mathrm{GA}_{29}$-catabolite was assumed to make a relatively insignificant contribution to ${ }^{3} \mathrm{H}$ release by PsGA2OX1 under the conditions of assay. This 
assumption was based on previous findings [4,14,15]. Similarly, it was assumed that AtGA3OX4 produced insignificant amounts of $\mathrm{GA}_{5}$ [4]. It should be noted that the kinetic parameters may be influenced by the presence of the label in the substrate due to a tritium isotope effect.

The standard assays were conducted using cofactors concentrations of established methods e.g. [14]. Reactions were in a volume of $200 \mu \mathrm{L}$ with $100 \mathrm{mM}$ Tris- $\mathrm{HCl} \mathrm{pH}$ 7.9, $4 \mathrm{mM}$ ascorbate, $4 \mathrm{mM}$ DTT, $4 \mathrm{mM}$ 2-oxoglutarate, 0.5 $\mathrm{mM} \mathrm{FeSO}_{4}, 2 \mathrm{mg} / \mathrm{mL}$ BSA and $1 \mathrm{mg} / \mathrm{mL}$ catalase. Substrate ( $5 \mu \mathrm{L}$ in methanol) was added to a concentration of $0.02 \mu \mathrm{M}$ for PsGA2OX1 assays and $0.1 \mu \mathrm{M}$ for AtGA3OX4 assays. The enzyme solution was added in volumes ranging from 1 to $50 \mu \mathrm{L}$. Highly active solutions were serially diluted using $1 \mathrm{mg} / \mathrm{mL}$ BSA before addition. The reactions took place at $30^{\circ} \mathrm{C}$ and were stopped with $25 \mu \mathrm{L}$ acetic acid after $1 \mathrm{~h}$. Labelled $\mathrm{GA}_{20}$ was precipitated by adding $780 \mu \mathrm{L}$ of $25 \mathrm{mM}$ EDTA containing $50 \mathrm{mg} / \mathrm{mL}$ activated charcoal and centrifuging at 5,000 rev/min for $5 \mathrm{~min}$. The release of tritiated water was measured by radiocounting a $300 \mu \mathrm{L}$ reaction aliquot in scintillation fluid with tritium standards alongside. The specific activity figures for each purification stage were derived from enzyme samples (or dilutions of samples) showing similar rates of product conversion.

The substrate, $\left[{ }^{3} \mathrm{H}_{3}\right] \mathrm{GA}_{20}$, was varied in the assays for kinetic studies as shown in Figures 3 and 5. At higher substrate concentrations the maximum volume of methanol added was $10 \mu \mathrm{L}$ (the extra methanol was shown not to be inhibitory). The amount of enzyme added was $1 \mu \mathrm{g}$ for PsGA2OX1 and $0.1 \mu \mathrm{g}$ for AtGA3OX4. Results were analysed using Origin by MicroCal.

\section{List of abbreviations}

GA - gibberellin

GST - glutathione-s-transferase

IMAC - immobilised metal affinity chromatography

kat - katal

$\beta$-ME - $\beta$-mercaptoethanol

2ODD - 2-oxoglutarate-dependent dioxygenase

PBS - phosphate-buffered saline

PCR - polymerase chain reaction

PMSF - phenylmethylsulfonyl fluoride

TRX - thioredoxin

\section{Authors' contributions}

DRL designed and performed most of the experimental work. She also drafted the manuscript. AP and PH developed the vector that enabled expression and purification of AtGA3OX4. IA conceived of the project, participated in experimental design and helped draft the manuscript. All authors read and contributed to the final draft of the manuscript.

\section{Acknowledgements}

This work was supported by the Swedish Research Council for Environment, Agricultural Sciences and Spatial Planning and the Swedish Research Council. Rothamsted Research is supported by the Biotechnology and Biological Sciences Research Council of the U.K.

Thanks to John Ross, School of Plant Science, University of Tasmania, for assistance with activity assays.

\section{References}

I. Sakamoto T, Miura K, Itoh H, Tatsumi T, Ueguchi-Tanaka M, Ishiyama K, Kobayashi M, Agrawal GK, Takeda S, Abe K, Miyao A, Hirochika $\mathrm{H}$, Kitano H, Ashikari M, Matsuoka M: An overview of gibberellin metabolism enzyme genes and their related mutants in rice. Plant Physiology 2004, I 34:1642-1653.

2. Hedden P, Phillips AL: Gibberellin metabolism: new insights revealed by the genes. Trends in Plant Science 2000, 5:523-530.

3. Frisse A, Pimenta MJ, Lange T: Expression studies of gibberellin oxidases in developing pumpkin seeds. Plant Physiology 2003, 131:1220-1227.

4. King RW, Junttila O, Mander LN, Beck EJ: Gibberellin structure and function: biological activity and competitive inhibition of gibberellin 2- and 3-oxidases. Physiologia Plantarum 2004, 1 20:287-297.

5. Schomburg FM, Bizzell CM, Lee DJ, Zeevaart JAD, Amasino RM: Overexpression of a novel class of gibberellin 2-oxidases decreases gibberellin levels and creates dwarf plants. Plant Cell 2003, 15:15I-163.

6. Williams J, Phillips AL, Gaskin P, Hedden P: Function and substrate specificity of the gibberellin $3 \beta$-hydroxylase encoded by the Arabidopsis GA4 gene. Plant Physiology 1998, 1 1 7:559-563.

7. Zhou R, Yu M, Pharis RP: 16,17-Dihydro gibberellin competitively inhibits a recombinant Arabidopsis GA 3 $\beta$-hydroxylase encoded by the GA4 gene. Plant Physiology 2004, 135:1000-1007.

8. Griggs DL, Hedden P, Lazarus CM: Partial purification of two gibberellin 2 $\beta$-hydroxylases from cotyledons of Phaseolus vulgaris. Phytochemistry 1991, 30:2507-25I2.

9. Kwak SS, Kamiya Y, Sakurai A, Takahashi N, Graebe JE: Partial purification and characterization of gibberellin $3 \beta$-hydroxylase from immature seeds of Phaseolus vulgaris L. Plant Cell Physiology 1988, 29:935-943.

10. Lange T, Schweimer A, Ward DA, Hedden P, Graebe JE: Separation and characterization of three 2-oxoglutarate-dependent dioxygenases from Cucurbita maxima $L$. endosperm involved in gibberellin biosynthesis. Planta 1994, 195:98-107.

II. Smith VA, MacMillan J: The partial purification and characterisation of gibberellin $2 \beta$-hydroxylases from seeds of Pisum sativum. Planta 1986, 167:9-18.

12. Lange T: Purification and partial amino-acid sequence of gibberellin 20-oxidase from Cucurbita maxima endosperm. Planta 1994, 195: 108-II5.

13. Lester DR, Ross J], Davies PJ, Reid JB: Mendel's stem length gene (Le) encodes a gibberellin 3ß-hydroxylase. Plant Cell 1997, 9:1435-1443.

14. Lester DR, Ross JJ, Smith JJ, Elliott RC, Reid JB: Gibberellin 2-oxidation and the SLN gene of Pisum sativum. Plant Journal 1999, 19:65-73.

15. Martin DN, Proebsting WM, Hedden P: The SLENDER gene of pea encodes a gibberellin 2-oxidase. Plant Physiology 1999, | 2 I:775-78|. 
16. Ross JJ, Reid JB, Swain SM: Control of stem elongation by gibberellin AI : Evidence from genetic studies including the slender mutant sln. Australian Journal of Plant Physiology 1993, 20:585-599.

17. Lukacin R, Gröning I, Schilz E, Britsch L, Matern U: Purification of recombinant flavanone 3 $\beta$-hydroxylase from Petunia hybrida and assignment of the primary site of proteolytic degradation. Archives of Biochemistry and Biophysics 2000, 375:364-370.

18. Curaba J, Moritz T, Blervaque R, Parcy F, Raz V, Herzog M, Vachon G: AtGA3ox2, a Key Gene Responsible for Bioactive Gibberellin Biosynthesis, Is Regulated during Embryogenesis by LEAFY COTYLEDON2 and FUSCA3 in Arabidopsis. Plant Physiology 2004, I 36:3660-3669.

19. Anzellotti D, Ibrahim RK: Molecular characterization and functional expression of flavonol 6-hydroxylase. BMC Plant Biology 2004, 4:20.

20. Turnbull JJ, Prescott AG, Schofield CJ, Wilmouth RC: Purification, crystallization and preliminary X-ray diffraction of anthocyanidin synthase from Arabidopsis thaliana. Acta Crystallographica D 200I, 57:425-427.

21. Wilmouth RC, Turnbull JJ, Welford RWD, Clifton IJ, Prescott AG, Schofield Cl: Structure and mechanism of anthocyanidin synthase from Arabidopsis thaliana. Structure 2002, 10:93-103.

22. Zhang Z, Ren JS, Clifton IJ, Schofield C): Crystal structure and mechanistic implications of I-aminocyclopropane-I-carboxylic acid oxidase - the ethylene-forming enzyme. Chemistry and Biology 2004, I I:1383-1394.

23. Willis CL, Gaskin P, MacMillan J: [I $\beta, 2 \beta, 3 \beta-3 H 3]$ gibberellin GA20: Confirmation of structure by $3 \mathrm{H}$ NMR and by mass spectrometry. Phytochemistry 1988, 27:3970-3972.

Publish with Biomed Central and every scientist can read your work free of charge

"BioMed Central will be the most significant development for disseminating the results of biomedical research in our lifetime. "

Sir Paul Nurse, Cancer Research UK

Your research papers will be:

- available free of charge to the entire biomedical community

- peer reviewed and published immediately upon acceptance

- cited in PubMed and archived on PubMed Central

- yours - you keep the copyright 